\title{
Content and Functionality of United States Medical School Websites
}

Jordan R. Pollock ${ }^{1}$, Michael L. Moore ${ }^{1}$, Jacob F. Smith ${ }^{1}$, Jonny B. Woolstenhulme ${ }^{2}$, Dane J. Markham ${ }^{3}$, Joshua R. Rhees ${ }^{4}$, Kenneth Poole ${ }^{5}$, Nathan T. Pollock ${ }^{4}$, Naresh P. Patel 6

1. Orthopedic Surgery, Mayo Clinic Alix School of Medicine, Scottsdale, USA 2. Dermatology, University of Utah School of Medicine, Salt Lake City, USA 3. Otolaryngology, Mayo Clinic Alix School of Medicine, Scottsdale, USA 4. Life Sciences, Brigham Young University, Provo, USA 5. Internal Medicine, Mayo Clinic Hospital, Phoenix, USA 6. Neurosurgery, Mayo Clinic Hospital, Phoenix, USA

Corresponding author: Naresh P. Patel, patel.naresh@mayo.edu

\section{Abstract}

Introduction

Most medical school applicants use the internet as a source of information when applying for medical school. Previous analyses have evaluated residency and fellowship websites; however, an in-depth analysis of medical school websites is lacking.

Methods

We evaluated 192 United States (US) medical school websites for presence or absence of 39 items relevant to medical school applicants. Items fell into seven general categories: curriculum, research, demographics of incoming class, admissions information, faculty, financial aid, and social.

Results

Of the 192 websites evaluated (152 allopathic and 40 osteopathic schools), websites contained a mean of 23 items (59\%) with a standard deviation of 4.2 items.

Conclusion

Our study examining US medical school websites revealed a lack of online information for medical school applicants. As medical school interviews transition to being online during the COVID-19 pandemic, the importance of the medical school website to applicants becomes increasingly crucial. The information contained in our study could be used to improve the functionality and quality of information on medical school websites, which could help both applicants and the medical schools themselves.

Review began 04/14/2021 Review ended 05/26/2021 Published 06/08/2021

๑) Copyright 2021 Pollock et al. This is an open access article distributed under the terms of the Creative Commons Attribution License CC-BY 4.0., which permits unrestricted use, distribution, and reproduction in any medium, provided the original author and source are credited.
Categories: Medical Education, Ouality Improvement, Other

Keywords: medical school, medical school education, medical school wesbite, medical school website content, medical school application, medical school applicant, covid-19, online interview, medical school interview

\section{Introduction}

Medical school is highly competitive. The acceptance rate of admissions was $41.9 \%$ from 2017 through 2020 , with an increasing number of applicants each year - 44,869, 51,067, and 52,326 applicants in 2017, 2018, and 2019, respectively [1]. Historically, prospective medical students obtained information about different medical schools through the Medical School Admissions Requirement (MSAR) paper book, summer programs, school advisors, and fairs sponsored by undergraduate institutions. Recently, however, the Association of American Medical Colleges (AAMC) suggests looking at each school's website for program information [2]. In May 2020, a group of national medical education organizations named the Coalition for Physician Accountability made specific recommendations to medical schools and residencies due to the COVID-19 pandemic. These recommendations are predicted to affect at least the 2020 through 2021 application cycle and will significantly limit opportunities for personal interactions between medical school applicants and medical schools [3]. Accordingly, website development, content, and functionality are increasingly important for medical schools. Prior studies have evaluated these factors among residency and fellowship programs, resulting in various recommendations for areas of improvement among their respective program websites to both help applicants and increase recruitment [4-10].

Comprehensive websites can help applicants make informed decisions, providing them with access to information they deem important. For the application cycle of 2019 to 2020, medical school applicants applied to an average of 17 medical schools according to the data recently released by the Association of American Medical Colleges [1]. Medical school applications and interviews are costly for both applicants and 
programs. Providing applicants with more information to guide decisions regarding which programs to apply to and interview at stands to benefit both parties, especially if it results in better matching of applicants likely to fit a school. Medical schools also stand to benefit from the better matching of applicants, as many institutions fill residency positions with recent graduates from their own programs. The astounding number of applications could be due to the increasingly competitive nature of the medical school or stress and concern for medical school acceptance. These factors may be accentuated during the COVID-19 pandemic as the Medical College Admissions Test (MCAT) has become delayed, and many service and shadowing opportunities have been canceled [11].

As medical school applicants apply to, interview at, and ultimately decide which institution to attend, careful planning and research is essential. The internet is easily accessible and multiple studies have shown the importance of websites in recruitment for residency, which likely applies to students applying for medical school as well [5, 8-9]. Medical schools spend substantial time and effort recruiting competitive and diverse students throughout the year with advertisements, information sessions, carefully planned interview days, second-look weekends, phone calls, financial aid offers, and more [12]. While these efforts will continue to be important, maintaining a medical school website with adequate information and quality is paramount, particularly for today's prospective students. For example, a survey of medical school students applying for residency found that $41 \%$ of applicants decided not to apply to at least one program solely based on the quality of its residency website, and $78 \%$ of applicants claimed information provided in the residency program website influenced their decision to apply to a particular program [13].

Information sources, such as the MSAR online database and the American Osteopathic Association (AOA) website, were designed to assist medical school applicants while applying for medical school [14-15]. Given the growing reliance on technology to do personal research on different medical schools, the need for prospective medical students to find robust, consistent information online will continue to increase. The main purpose of our study is to provide an in-depth analysis of medical school website content and to assess the functionality of MSAR and AOA for prospective medical school applicants. To our knowledge, this study is the first to do an in-depth analysis of medical school websites in the United States.

This paper was previously posted on the Research Square preprint server on January 22, 2021 (doi: 10.21203/rs.3.rs-147236/v1; http://www.researchsquare.com/article/rs-147236/v1).

\section{Materials And Methods}

The methods of our study were adapted from a well-conceived study examining otolaryngology residency website content [5]. Our study was exempt from Institutional Review Board (IRB) approval because it involves publicly available information. A list of 192 medical school names and website links were obtained from Medical School and Admissions Requirements (MSAR) online database and the American Osteopathic Association (AOA) website in May 2020 [14-15]. We evaluated both information sources for functionality by determining whether the link provided on MSAR or AOA led directly to the medical school homepage or required multiple clicks to get to the medical school homepage. When a link to a program was not available on MSAR or AOA website, we performed a Google search to find the program website. Medical schools without a functional website, or a website that could not be found, were excluded $(n=2)$.

The data were collected by four authors (JW, JS, DM, JR) between May 2020 and June 2020. Data gatherers searched the websites of these programs for 39 items listed in Table 1 . These items were later divided into seven categories for further analysis: curriculum, research, demographics of the incoming class, admissions information, faculty, financial aid, and social. The items and categories included in our study are based on variables many applicants deem as necessary or desirable information, as well as variables we believe are important to medical school applicants [13]. We also included items from a variety of studies examining the quality of residency website content and based our seven categories on these studies [4-6, 9-10]. Variables were also added to our study based on the discretion of the authors of this study, including pre-medical students, medical students, and physicians. Some of these factors on medical school websites could be more important to applicants than other factors, as suggested by studies examining how medical students choose a residency program [16-17]. However, we controlled for this by examining a large number of items (39) on each website and based these items on a variety of studies, as previously described.

\begin{tabular}{|c|c|c|c|c|}
\hline Comparison Variables & $\begin{array}{l}\text { Number of MD Programs } \\
\text { (\% of all MD Programs) }\end{array}$ & $\begin{array}{l}\text { Number of DO Programs } \\
\text { (\% of all DO Programs) }\end{array}$ & $\begin{array}{l}\text { Number of MD + DO Programs (\% } \\
\text { of all MD and DO Programs) }\end{array}$ & $\begin{array}{l}\mathrm{P} \text { - } \\
\text { value }\end{array}$ \\
\hline \multicolumn{5}{|l|}{ Curriculum } \\
\hline Yearly Overview Listed & $146(96.1 \%)$ & $40(100.0 \%)$ & $186(96.9 \%)$ & 0.471 \\
\hline Attendance Policy Listed & $42(27.6 \%)$ & $10(25.0 \%)$ & $52(27.1 \%)$ & 0.973 \\
\hline $\begin{array}{l}\text { Evaluation (Grading) } \\
\text { Policy Listed }\end{array}$ & $57(37.5 \%)$ & $8(20.0 \%)$ & $65(33.9 \%)$ & 0.147 \\
\hline
\end{tabular}




\section{Cureus}

\begin{tabular}{|c|c|c|c|c|}
\hline $\begin{array}{l}\text { Dual Degree Programs } \\
\text { Listed }\end{array}$ & $127(83.6 \%)$ & $21(52.5 \%)$ & 148 (77.1\%) & 0.108 \\
\hline Match Results Listed & $103(67.8 \%)$ & $29(72.5 \%)$ & $132(68.8 \%)$ & 0.458 \\
\hline $\begin{array}{l}\text { Average USMLE Step } 1 \\
\text { Score }\end{array}$ & $13(8.6 \%)$ & $0(0.0 \%)$ & $13(6.8 \%)$ & 0.077 \\
\hline USMLE Step 1 Pass rate & $29(19.1 \%)$ & $1(2.5 \%)$ & $30(15.6 \%)$ & 0.026 \\
\hline Average COMLEX Score & - & $4(10.0 \%)$ & $4(10.0 \%)$ & - \\
\hline $\begin{array}{l}\text { COMLEX Pass Rate } \\
\text { Listed }\end{array}$ & - & $34(85.0 \%)$ & $34(85.0 \%)$ & - \\
\hline Facility Description & 75 (49.3\%) & $30(75.0 \%)$ & 105 (54.7\%) & 0.018 \\
\hline $\begin{array}{l}\text { Rotation Information } \\
\text { Provided }\end{array}$ & $109(71.7 \%)$ & $32(80.0 \%)$ & $141(73.4 \%)$ & 0.325 \\
\hline \multicolumn{5}{|l|}{ Research } \\
\hline $\begin{array}{l}\text { Description of Research } \\
\text { Opportunities }\end{array}$ & $127(83.6 \%)$ & $32(80.0 \%)$ & $159(82.8 \%)$ & 0.821 \\
\hline $\begin{array}{l}\text { Research Requirement } \\
\text { Information Listed }\end{array}$ & $45(29.6 \%)$ & $3(7.5 \%)$ & $48(25.0 \%)$ & 0.021 \\
\hline \multicolumn{5}{|c|}{ Demographics of Incoming Class } \\
\hline Demographics are Listed & 97 (63.8\%) & 20 (50.0\%) & 117 (60.9\%) & 0.526 \\
\hline MCAT Stats Listed & $111(73.0 \%)$ & 29 (72.5\%) & 140 (72.9\%) & 0.698 \\
\hline GPA Stats Listed & $115(75.7 \%)$ & $26(65.0 \%)$ & $141(73.4 \%)$ & 0.770 \\
\hline $\begin{array}{l}\text { State-by-State Data } \\
\text { Listed }\end{array}$ & 27 (17.8\%) & $9(22.5 \%)$ & $36(18.8 \%)$ & 0.397 \\
\hline \multicolumn{5}{|l|}{ Financial Aid } \\
\hline $\begin{array}{l}\text { Average Financial Aid } \\
\text { Listed }\end{array}$ & $7(4.6 \%)$ & $0(0.0 \%)$ & $7(3.6 \%)$ & 0.194 \\
\hline $\begin{array}{l}\text { Info on How to Apply For } \\
\text { Aid Listed }\end{array}$ & $140(92.1 \%)$ & 39 (97.5\%) & $179(93.2 \%)$ & 0.422 \\
\hline $\begin{array}{l}\text { Financial Aid Office } \\
\text { Contact Info Listed }\end{array}$ & $135(88.8 \%)$ & 39 (97.5\%) & 174 (90.6\%) & 0.317 \\
\hline $\begin{array}{l}\text { Scholarship Opportunities } \\
\text { Listed }\end{array}$ & 99 (65.1\%) & 37 (92.5\%) & $136(70.8 \%)$ & 0.022 \\
\hline Example Budget Listed & $137(90.1 \%)$ & 33 (82.5\%) & $170(88.5 \%)$ & 0.999 \\
\hline \multicolumn{5}{|l|}{ Admissions Info } \\
\hline $\begin{array}{l}\text { Required Pre-Med } \\
\text { Courses Listed }\end{array}$ & 145 (95.4\%) & 40 (100.0\%) & 185 (96.4\%) & 0.448 \\
\hline $\begin{array}{l}\text { Letters of Rec } \\
\text { Requirements Listed }\end{array}$ & 141 (92.8\%) & 37 (92.5\%) & 178 (92.7\%) & 0.644 \\
\hline $\begin{array}{l}\text { Admissions Office } \\
\text { Contact Info Listed }\end{array}$ & 144 (94.7\%) & 38 (95.0\%) & $182(94.8 \%)$ & 0.618 \\
\hline $\begin{array}{l}\text { Waitlist Information } \\
\text { Provided }\end{array}$ & 55 (36.2\%) & $5(12.5 \%)$ & 60 (31.3\%) & 0.030 \\
\hline $\begin{array}{l}\text { Early Decision Program } \\
\text { Info Provided }\end{array}$ & 89 (58.6\%) & 7 (17.5\%) & 96 (50.0\%) & 0.003 \\
\hline Acceptance Rate Listed & 79 (52.0\%) & $14(35.0 \%)$ & $93(48.4 \%)$ & 0.288 \\
\hline $\begin{array}{l}\text { In vs Out-of-State } \\
\text { Preference listed }\end{array}$ & 59 (38.8\%) & 2 (30.0\%) & $71(37.0 \%)$ & 0.592 \\
\hline
\end{tabular}




\section{Cureus}

\begin{tabular}{|c|c|c|c|c|}
\hline $\begin{array}{l}\text { Interview/Decision Timing } \\
\text { Listed }\end{array}$ & $115(75.7 \%)$ & 17 (42.5\%) & $132(68.8 \%)$ & 0.058 \\
\hline US News Ranking Listed & $28(18.4 \%)$ & $2(5.0 \%)$ & $30(15.6 \%)$ & 0.078 \\
\hline \multicolumn{5}{|l|}{ Social Environment } \\
\hline $\begin{array}{l}\text { Student Wellness } \\
\text { Resources Listed }\end{array}$ & $136(89.5 \%)$ & $36(90.0 \%)$ & $172(89.6 \%)$ & 0.615 \\
\hline $\begin{array}{l}\text { Med School Social Media } \\
\text { Link(s) Listed }\end{array}$ & $129(84.9 \%)$ & 33 (82.5\%) & $162(84.4 \%)$ & 0.759 \\
\hline $\begin{array}{l}\text { Description of Area } \\
\text { Activities/Highlights } \\
\text { Listed }\end{array}$ & $106(69.7 \%)$ & 28 (70.0\%) & 134 (69.8\%) & 0.665 \\
\hline $\begin{array}{l}\text { Clubs/Interest Groups } \\
\text { Listed }\end{array}$ & $122(80.3 \%)$ & $33(82.5 \%)$ & $155(80.7 \%)$ & 0.555 \\
\hline \multicolumn{5}{|l|}{ Faculty } \\
\hline Faculty Listed & $131(86.2 \%)$ & 38 (95.0\%) & $169(88.0 \%)$ & 0.313 \\
\hline Photos Listed & $112(73.7 \%)$ & 32 (80.0\%) & $144(75.0 \%)$ & 0.394 \\
\hline $\begin{array}{l}\text { Student/Faculty Ratio } \\
\text { Listed }\end{array}$ & 33 (21.7\%) & 4 (10.0\%) & 37 (19.3\%) & 0.186 \\
\hline $\begin{array}{l}\text { Faculty Research } \\
\text { Interests Listed }\end{array}$ & $109(71.7 \%)$ & $23(57.5 \%)$ & $132(68.8 \%)$ & 0.563 \\
\hline
\end{tabular}

As the data contained in residency websites can be subjective, we created a standardized process to evaluate the websites, similar to the previous studies in other specialties [4-8]. First, we only searched for the presence or absence of items, with no attempt made to grade the quality or accuracy of the content. Second, any information that was not directly listed on the medical school website was excluded, such as links to external materials or websites, which usually contained general, non-specific information rather than medical school-specific information. Lastly, data were gathered independently by four authors for the same 10 programs and compared for agreement. All authors went through all items again together, noting where a disagreement occurred. Ambiguity in exclusion and inclusion criteria was resolved and adjusted accordingly upon agreement by all authors. After this instruction, data collectors independently gathered the data for all websites (JW, JS, DM, JR, LM). Each website was reviewed by two authors independently, and a third author resolved the disagreement. We performed a descriptive analysis of the data, including means and standard deviations. Additionally, a sub-analysis was performed to determine whether a difference existed in website quality and functionality among the top 25 medical schools and the other 167 schools in our study. We referred to the 2021 data from the US News and World Report website for best medical schools for research, which attempts to rank medical schools based on a variety of criteria [18]. Microsoft ${ }^{\circledR}$ Excel $^{\circledR}$ was used for statistical analysis (Microsoft ${ }^{\circledR}$ Corp., Redmond, WA).

\section{Results}

Of the 192 websites evaluated (152 allopathic and 40 osteopathic schools), websites contained a mean of 23 items (59\%) with a standard deviation of 4.2 items. We found a statistically significant difference between allopathic and osteopathic programs $(\mathrm{p}<0.05)$ for six of the 39 variables included in our study. Of these six variables, Doctor of Osteopathy (DO) programs included facility description and scholarship opportunities more frequently than Doctor of Medicine (MD) schools, while MD programs included United States Medical Licensing Examination (USMLE) Step 1 pass rate, research requirement information listed, waitlist information provided, and early decision information provided more frequently. The variables contained least frequently among all medical schools were average financial aid amount (3.6\%), average USMLE Step 1 score (6.8\%), USMLE Step 1 pass rate (15.6\%), and US News and World Report ranking (15.6\%). The variables contained most frequently were yearly overview (96.9\%), required pre-medical courses (96.4\%), admissions office contact information (94.8\%), and information on how to apply for financial aid (93.2\%) (Table 1). 


\section{Cureus}

The categories with the most amount of information across both allopathic and osteopathic schools were the social and financial aid categories, with $81 \%$ and $69 \%$ of the websites containing this information, respectively. The categories with the least number of variables were the curriculum and research categories at $50 \%$ and $54 \%$, respectively. Allopathic websites were more likely to contain variables relating to curriculum, research, demographics, admissions information, and faculty, while osteopathic websites were more likely to contain information in the financial aid and social categories (Figure 1).

\section{Content on Osteopathic and Allopathic Medical School Websites}

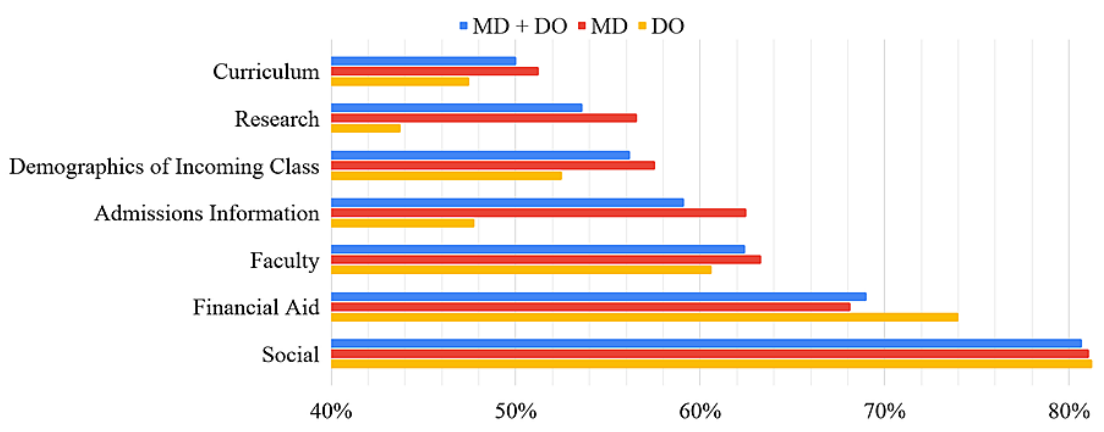

FIGURE 1: Content analysis comparing osteopathic and allopathic medical school websites

DO: Doctor of Osteopathic Medicine; MD: Doctor of Medicine

Medical school websites from US News and World Report top 25 schools contained more of the 39 variables than schools from non-top 25 programs, with statistical significance demonstrated with variables, such as research requirement, average financial aid, in-state vs out-of-state preference listed, and US News and World Report ranking listed (Table 2) [18]. Medical school websites from top 25 schools had more variables listed on average in each of the seven general categories when compared to the other non-top 25 programs (Figure 2).

Comparison Variables
Curriculum
Yearly Overview Listed
Attendance Policy Listed
Evaluation (Grading) Policy
Listed
Dual Degree Programs Listed
Match results listed
Average USMLE Step 1 Score
USMLE Step 1 Pass Rate
Average COMLEX Score
COMLEX Pass Rate Listed

Number of Top 25 Programs (\% of all Top 25 Programs)

$25(100.0 \%)$

$12(48.0 \%)$

$13(52.0 \%)$

$25(100.0 \%)$

$17(68.0 \%)$

$1(4.0 \%)$

$3(12.0 \%)$

$-$

$12(48.0 \%)$

$22(88.0 \%)$

Research

Description of Research

Opportunities

$21(84.0 \%)$

Research Requirement Information Listed
$138(82.6 \%)$

0.661

Number of Non-Top 25 Programs (\% of all Non-Top 25 Programs)

Pvalue

$161(96.4 \%)$

0.702

$40(24.0 \%)$

0.076

$52(31.1 \%)$

0.201

$123(73.7 \%)$

0.394

$115(68.9 \%)$

0.612

$12(7.2 \%)$

0.489

27 (16.2\%)

0.490

$4(10.0 \%)$

$34(85.0 \%)$

$93(55.7 \%)$

0.382

119 (71.3\%)

0.691

$31(18.6 \%)$ 


\section{Cureus}

Demographics of Incoming Class

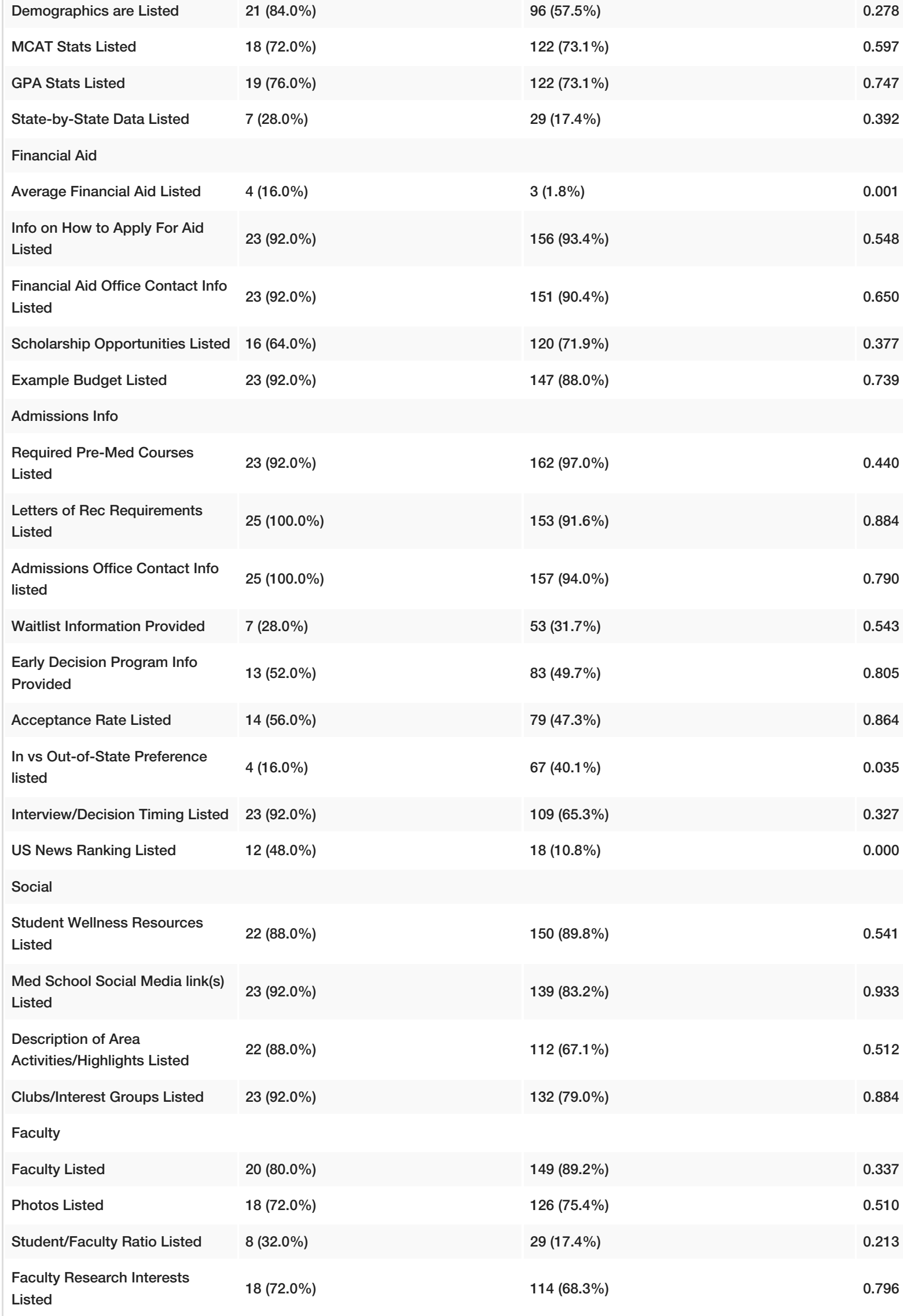

TABLE 2: A Comparison of Variables Found on Top 25 Medical School Websites Compared to 


\section{Other Non-Top 25 School Websites}

COMLEX: Comprehensive Osteopathic Medical Licensing Examination; GPA: grade point average; Info: information; MCAT: Medical College Admission Test; Pre-Med: Pre-medical; Rec: recommendation; Stats: statistics; US: United States; USMLE - United States Medical Licensing Examination

\section{Content on Top 25 Ranked vs All Other Medical School Websites}

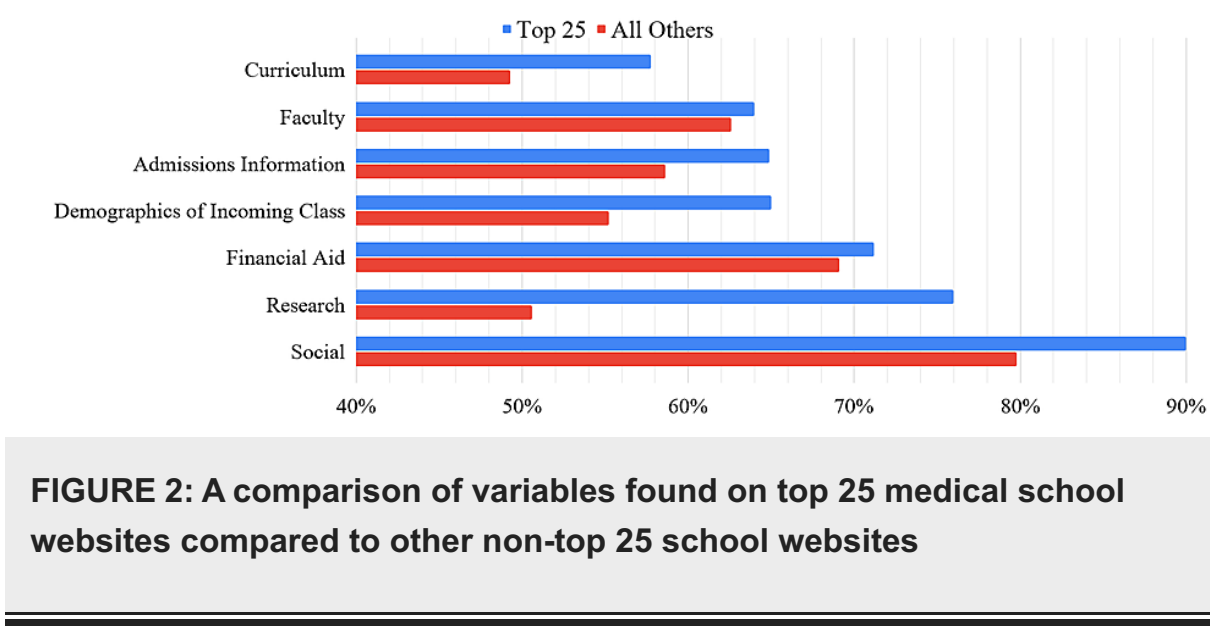

Lastly, in terms of website accessibility, $89 \%$ of medical school program listings on the MSAR database or the AOA website provided direct links, $10 \%$ provided absent or non-functional links, and $1 \%$ provided indirect links.

\section{Discussion}

A recent study examining prospective students' medical school preferences reported the most important factors for medical school choice were academic prestige, location, and the "intangibles," such as "gut feelings" and personal interactions [19]. According to our study, medical schools rarely included the US News and World Report rankings on their websites, average USMLE Step 1 score, or USMLE Step 1 pass/fail rate. These factors, which are associated with the prestige of the school, should be incorporated into medical school websites. With regards to location, medical schools provided descriptions of the location of the medical school nearly $70 \%$ of the time. This becomes increasingly important with online interviews as many applicants may not be able to see the area for themselves. Another area for improvement for medical school websites could be providing state-by-state demographic information, which was only listed $19 \%$ of the time. However, the "intangibles," such as "gut feelings" and personal interactions, were student wellness resources listed, clubs and interest groups, and social media links which were listed $90 \%, 81 \%$, and $84 \%$ of the time, respectively. This shows medical schools are likely aware of the "intangibles" and attempt to address them with more personal and social content.

With the rise of social media for recreational and professional purposes, integrating social media effectively and efficiently could help medical schools recruit desired applicants and help applicants learn more about different schools. We found $84 \%$ of medical schools' websites contained links to a form of social media representing their program, but $16 \%$ of programs did not have a directly accessible social media page for their program. This suggests an area for improvement. Having a social media site available for applicants could prove useful to students and programs, as a study done involving nearly 1,000 medical students applying for residency showed that $68 \%$ of students reported using social media to learn about programs and $10 \%$ reported that the information found in the social media pages influenced their decisions on where to apply [20]. Similarly, a survey of medical students applying for residency suggested social media as an efficient method for highlighting social activities to improve recruitment [21].

Information on current enrolled medical students, such as class demographics and state-by-state data, may be the only exposure of such applicants to the unique personalities and backgrounds of students in the program before deciding to apply to a program. Class demographics and state-by-state data were only listed on $61 \%$ and $19 \%$ of medical school websites, respectively. Medical schools may benefit from improving these sections of their websites. We also found medical school websites do not have much information pertaining to individual students. However, many residency websites often include photos of the class, photos of each individual student, and small, personal descriptions of each resident. This is an area for medical school websites to give more personalization to their program. Of course, maintaining the appropriate confidentiality of the students should be considered. 
For example, attendance policy was only listed on $27 \%$ of websites, grading policies were listed on $34 \%$ of websites, and research requirement information was listed on $25 \%$ of websites. As medical education becomes more personalized, descriptive details of programs could help students choose a school based on their unique learning styles [22-24]. These details are essential as applicants choose to which programs they will apply. Also, while many of these topics are discussed during interviews, these details can be forgotten or unclear, and a more robust website would be useful in addressing these important questions when medical students are deciding which school to attend. Including more information on curriculum and research could help medical students decide which programs to apply to and attend and help programs recruit students who are a better fit for the curriculum of the school. Recent articles have suggested that residency programs expand the amount of information for applicants during the COVID-19 interview cycle, and perhaps the same should apply to medical schools [25].

While some aspects of medical school websites are lacking, we found medical school website links to be functional through the MSAR database and the AOA website. Of the 192 medical schools examined in our study, $89 \%$ of medical school program listings in AOA or MSAR provided direct links, while only $10 \%$ were absent or non-functional and $1 \%$ were indirect links. However, the number of multiple-step, absent, and non-functional links could still be improved.

The top 25 schools in the US, according to the US News and World Report 2021, had more study variables listed on their websites than non-top 25 schools, such as information on the research requirement and average financial aid. In addition, allopathic websites were more likely to contain variables relating to curriculum, research, demographics, admissions information, and faculty, while osteopathic websites were more likely to contain information in the financial aid and social categories [18]. Future investigations should determine why these differences exist, and whether these differences affect prospective student recruitment. Future research should aim to determine how the COVID-19 pandemic and lack of online information on medical school websites could be affecting the number of applications submitted per applicant.

Limitations of our study include the subjective nature of analyzing medical school websites. However, we feel our method of data collection was standardized sufficiently to control for ambiguity. Another limitation was the lack of established standardized criteria for evaluating websites. Every item that could be important to a medical school applicant was not analyzed. As a solution, we included a variety of items and developed search criteria based on studies evaluating residency website content and the recent experience of the authors of our study. Lastly, only including items listed directly on the medical school website rather than on external links could underestimate the presence of items on websites in our study. However, this was an important factor to determine the accessibility and functionality of information and the user-friendly status of the websites. Our study does not address the accuracy or quality of information contained on websites. Notwithstanding these limitations, we believe our analysis provides valuable insight for medical school directors, website developers, and medical school applicants. Future areas of study could include an indepth analysis of social media use among medical schools, how website quality affects the number of medical school applications, and why differences in website content exist between different programs, such as allopathic, osteopathic, and the US News and World Report top 25 schools.

\section{Conclusions}

The 2020-21 residency application cycle poses a new challenge for applicants and programs. As most interviews are being conducted on a virtual platform, interview costs are less of an issue for applicants, which could drive up the number of programs that students apply to and consider. A robust source of information available to applicants on medical school websites serves to benefit both the applicant and program alike to prevent overwhelming medical schools with applications and interviewees.

Medical school website quality is important to medical school applicants, and our study identifies several areas where programs could focus efforts for website renovation. The categories of variables which are included least frequently on medical school websites are variables related to curriculum, research, demographics, and admissions information. The results from our study can be used to improve medical school websites to the benefit of applicants and medical schools.

\section{Additional Information}

\section{Disclosures}

Human subjects: All authors have confirmed that this study did not involve human participants or tissue. Animal subjects: All authors have confirmed that this study did not involve animal subjects or tissue. Conflicts of interest: In compliance with the ICMJE uniform disclosure form, all authors declare the following: Payment/services info: All authors have declared that no financial support was received from any organization for the submitted work. Financial relationships: All authors have declared that they have no financial relationships at present or within the previous three years with any organizations that might have an interest in the submitted work. Other relationships: All authors have declared that there are no other relationships or activities that could appear to have influenced the submitted work. 


\section{References}

1. 2020 FACTS: Applicants and Matriculants Data . (2019). Accessed: August 9, 2020: http://www.aamc.org/data-reports/students-residents/interactive-data/2019-facts-applicants-andmatriculants-data.

2. Deciding Where to Apply. (2020). Accessed: August 9, 2020: http://residents.aamc.org/applying-medicalschool/applying-medical-school-process/deciding-where-apply/..

3. Reports From The Coalition For Physician Accountability . (2020). Accessed: June 30, 2020: http://www.nrmp.org/coalition-physician-accountability-documents/.

4. Silvestre J, Tomlinson-Hansen S, Fosnot J, Taylor JA: Plastic surgery residency websites: a critical analysis of accessibility and content. Ann Plast Surg. 2014, 72:265-69. 10.1097/SAP.0000000000000125

5. Svider PF, Gupta A, Johnson AP, Zuliani G, Shkoukani MA, Eloy JA, Folbe AJ: Evaluation of otolaryngology residency program websites. JAMA Otolaryngol Head Neck Surg. 2014, 140:956-60. 10.1001/jamaoto.2014.1714

6. An Assessment of the Comprehensiveness of Radiation Oncology Residency Websites . (2020). Accessed: July 3, 2020: http://appliedradiationoncology.com/articles/an-assessment-of-the-comprehensiveness-ofradiation-oncology-residency-w...

7. Hamid S, Gibney B, Niu B, et al.: An evaluation of the content of Canadian and American nuclear medicine fellowship websites. Can Assoc Radiol J. 2020, 846537120913031. 10.1177/0846537120913031

8. Khan MS, Hayat J, Marsia S, et al.: How well do we represent ourselves: an analysis of cardiology fellowships website content. Future Cardiol. 2020, 16:281-87. 10.2217/fca-2019-0015

9. Oladeji LO, Yu JC, Oladeji AK, Ponce BA: How useful are orthopedic surgery residency web pages? . J Surg Educ. 2015, 72:1185-89. 10.1016/j.jsurg.2015.05.012

10. Patel BG, Gallo K, Cherullo EE, Chow AK: Content analysis of ACGME accredited urology residency program webpages. Urology. 2020, 138:11-15. 10.1016/j.urology.2019.11.053

11. How COVID-19 is affecting medical school admissions . (2020). Accessed: September 13, 2020: http://www.ama-assn.org/residents-students/preparing-medical-school/how-covid-19-affecting-medicalschool-admissions.

12. Medical School Interviews. (2020). Accessed: September 12, 2020: http://residents.aamc.org/applyingmedical-school/applying-medical-school-process/medical-school-interviews/..

13. Gaeta TJ, Birkhahn RH, Lamont D, Banga N, Bove JJ: Aspects of residency programs' web sites important to student applicants. Acad Emerg Med. 2005, 12:89-92. 10.1111/j.1553-2712.2005.tb01486.x

14. Medical School Admission Requirements. (2021). Accessed: August 9, 2020: http://apps.aamc.org/msar-ui/.

15. Osteopathic Medical Schools. (2020). Accessed: August 9, 2020: http://osteopathic.org/about/affiliatedorganizations/osteopathic-medical-schools/.

16. Deloney LA, Perrot LJ, Lensing SY, Jambhekar K: Radiology resident recruitment: a study of the impact of web-based information and interview day activities. Acad Radiol. 2014, 21:931-37. 10.1016/i.acra.2014.03.009

17. Zigrossi D, Ralls G, Martel M, et al.: Ranking programs: medical student strategies. J Emerg Med. 2019, 57:e141-e145. 10.1016/j.jemermed.2019.04.027

18. Explore the 2021 Best Medical Schools for Research. (2020). Accessed: August 9, 2020: http://www.usnews.com/education/best-graduate-schools/top-medical-schools/slideshows/us-news-bestmedical-schools-for...

19. Brown C: A qualitative study of medical school choice in the UK . Med Teach. 2007, 29:27-32. 10.1080/01421590601032419

20. Schweitzer J, Hannan A, Coren J: The role of social networking web sites in influencing residency decisions . J Am Osteopath Assoc. 2012, 112:673-679.

21. Mahler SA, Wagner MJ, Church A, Sokolosky M, Cline DM: Importance of residency program web sites to emergency medicine applicants. J Emerg Med. 2009, 36:83-88. 10.1016/j.jemermed.2007.10.055

22. Haiech J, Kilhoffer MC: Personalized medicine and education: the challenge. Croat Med J. 2012, 53:298-300. 10.3325/cmj.2012.53.298

23. Yovanoff M, Pepley D, Mirkin K, Moore J, Han D, Miller S: Personalized learning in medical education: designing a user interface for a dynamic haptic robotic trainer for central venous catheterization. Proc Hum Factors Ergon Soc Annu Meet. 2017, 61:615-19. 10.1177/1541931213601639

24. Toward More Personalized Learning. (2018). Accessed: September 12, 2020: http://www.hopkinsmedicine.org/news/articles/toward-more-personalized-learning-1.

25. Hammoud MM, Standiford T, Carmody JB: Potential implications of COVID-19 for the 2020-2021 residency application cycle. JAMA. 2020, 324:29-30. 10.1001/jama.2020.8911 